\title{
Resistance to a First-Time Online Training Course for Sport Technicians
}

\author{
Isabel Alvarez ${ }^{1, *} \&$ Carles Dulsat ${ }^{2}$ \\ ${ }^{1}$ Department of Systematic and Social Pedagogy, Autonomous University of Barcelona, Spain \\ ${ }^{2}$ Department of Pedagogy and Didactics, University of Coruña, Coruña, Spain \\ *Correspondence: Department of Systematic and Social Pedagogy, Autonomous University \\ of Barcelona, Spain. E-mail: isabel.alvarez@uab.cat
}

Received: December 7, 2016 Accepted: December 18, 2016 Published: December 22, 2016

doi:10.5296/ije.v8i4.10413 URL: http://dx.doi.org/10.5296/ije.v8i4.10413

\begin{abstract}
Decreasing enrollment at The Royal Spanish Skating Federation for Training Sport Technicians compelled the adoption of an online version of a training course. This paper identifies the resistance experienced by participants and explores the relations among four power variables: communication and participation, daily routines, flexibility of the courses, and training programs. Participants included students and instructors who completed a questionnaire. The results indicated that the students felt that they lack contact and interaction, leading to a feeling of apprehension. In addition, they had limited Internet access, which aggravated their lack of participation, isolating them and leaving them feeling inadequately informed. In contrast, the instructors focused their attention on the training programs. This paper proposes solutions and improvements for future versions of the course for redressing imbalances in power relationships among the participants.
\end{abstract}

Keywords: Power resistance, online training programs, Foucault. 


\section{Introduction}

It is difficult to define the concept of resistance and determine the types of resistance that are present in different educational and/or training contexts. Caruth and Caruth (2013) indicated this concept in innovation within the world of education. Further, we can find definitions of resistance specifically in relation to distance training as a foregrounded issue in training institutions (Macfayden \& Dawson, 2012; Szeto, 2013; Parlakkilic, 2013; Bulfin, Pangrazio, \& Selwyn, 2014; Han \& Han, 2014). More precisely, we can find reference to resistance in the context of innovations for teaching staff (Emo, 2015). This study represents an approach to the problem from the perspective of resistance arising essentially from an individual's perception of the concept of power.

Resistance is an integral part of the process of innovation and/or change (Bell \& Baron, 2015; Walker, Holling, Carpenter, Kinzig, 2004) or a typical response to dominant positions (Olafson, 2006; Sharp, 2000). Some authors have attributed a necessarily positive character to it (Kahnemann \& Tversky, 1979). Others, in contrast, have regarded it as negative, including its misalignment with organizations' plans, (Dent \& Goldberg, 1999) and suggest that action is required to generate solutions in the face of resistance. In this particular case, resistance was identified in the online implementation of a course for sport technicians for skating specialists. This was the first time the Spanish Skating Federation had proposed replacing its presential training with distance training. The first signs of resistance on the part of the participants did not take long to manifest themselves. They can be attributed to the following reasons: 1) It was the first time a change to this model had occurred, 2) the institution had had no previous experience of online learning, and 3) some could not understand how online training was possible for a course that required physical presence. This resistance was experienced by two levels of participants: students and instructors.

This study offers a new understanding of resistance based on the concept of power in a distance training course for sport technicians. It offers solutions based on the theoretical frameworks of Foucault (2012) and Molina (2006).

\subsection{Power and Resistance}

According to Foucault (1978), the concepts of power resistance are inseparably interrelated. Where there are power relationships, there will be resistance. Power and resistance are two interdependent concepts that constantly interact with each other. The exercise of power constantly generates knowledge, and resistance accumulates within the experience of the subjects, for whom it is their means of exercising their freedom. This exercise of freedom becomes a call for the "emancipating resistance" of individuals which, in turn, puts them in a state of constant alertness. In this manner, the ability to resist grows both in terms of individual action and collective movements (Molina, 2006).

Foucault (2012) regarded power as possessing three aspects: positivity, creativity, and productivity. Similarly, resistance can be defined in terms of these same three aspects: it is positive, active, and creative. The aim being pursued is the construction of a new subjectivity whereby the individual is given the power to modify the status quo. Furthermore, individuals 
relate to each other on the basis of the forces that keep them in contact with one another. This relationship is conducive to experiences being constructed, and needless to say, to their being able to be shared. In the same manner, resistance as a strategy has a positive effect, as it benefits individuals who are not participating in what they are doing. This participation will be active, sustained and, hopefully, interconnected (Molina 2006). Nevertheless, indicating that power is never one-dimensional and that it is wielded as an act of resistance is essential (Giroux, 2001).

This study seeks to explain the implementation of web-based communities in an educational system, in addition to online training. In this context, resistance must have the function of criticism vis-à-vis domination. In this regard, resistance will provide opportunities for self-reflection and both individual and social emancipation (Giroux, 2001). Thus, emancipating resistance will be the alternative and the vehicle for consciences to be mobilized (Bourdieu, 1998).

Foucault (2012) and Molina (2006) highlighted four variables for the study of individual resistance in any educational institution. These resistances are determined by the role of power, and it is in that context that their confluence can be understood. These four types of resistance are 1) communication and participation (possible difficulties involved in making our collaboration available), 2) the daily lives of the participants (focusing on the day-to-day routines of the participants), 3) the flexibility of the courses (the extent to which they can incorporate changes and remodeling), and 4) the training programs of the courses (syllabus and possible changes). These four variables will be applied to the case study presented in this paper, determining the causes of resistance and possible solutions for the participants in the study (both instructors and students).

\section{Methodology}

\subsection{Setting and Sample}

This study was conducted in three major Spanish cities: Coruña, Madrid, and Logroño. Data was drawn from the initial course for sports technicians organized by The Royal Spanish Skating Federation. Students filled in their questionnaires online. In contrast, the instructors preferred to fill in their questionnaires in person due to their teaching loads and the opportunity to have a meeting.

\subsection{Participants}

Participants $(\mathrm{N}=100)$ included $(\mathrm{N}=90)$ students and $(\mathrm{N}=10)$ instructors who completed the questionnaire. This reflects that $42 \%$ of students and $100 \%$ of the instructors responded. Of the students, $53.46 \%$ were women and $46.54 \%$ were men. Of the instructors, $20 \%$ were women and $80 \%$ were men. Furthermore, $43.4 \%$ student respondents had previous online experience; a significantly larger proportion of instructors $(70 \%)$ had previous online experience. Both students and instructors had participated in this particular course for the first time. No course credits or other rewards were given to participants who volunteered for this 
study.

\subsection{Instrument}

This paper uses a mixed method approach (Creswell, 20014). An ad hoc questionnaire was used, specifically created in accordance with the four variables defined by Foucault (2012) and Molina (2006). To validate the questionnaire, seven experts carefully examined it to identify any mistakes. The instrument tested four factors: 1) communication and participation, 2) flexibility, 3) daily lives, and 4) training programs. All responses were on a five-point Likert scale ranging from 1 (strongly disagree) to 5 (strongly agree). Each item had two quantitative entries. The survey contained 15 questions for the students' questionnaire and 16 for the instructors' questionnaire. The online questionnaire was developed using the SurveyMonkey platform.

Some items also included open-ended questions for which students and instructors could make comments regarding the particular score chosen for the five-point Likert scale; we later used these for quality control. Furthermore, these dual entries, quantitative and qualitative, served as a means of triangulating the data collection for further analysis (Denzin \& Licoln, 2007) and of improving the study's internal validity (Olabuénaga, 2003; Villa, 2003).

\subsection{Data Collection and Analysis}

Statistical data analysis was conducted using SPSS 22.0. For results obtained from the students, quantitative analysis used one-way ANOVA tools to determine the weighted average for more than one parametric group or a chi tables test when the samples were not homocedastic. As the teaching staff sample comprised 10 individuals, Mann-Whitney U tools were used for the two independent samples on median differences, and the Wilcoxon test was used to show how the two samples related with regard to their medians.

\section{Results}

\subsection{Quantitative}

Quantitative data was obtained concerning the participants in the online courses. Table 1 presents the level of participation and the flexibility of courses according to the participants. Thus, Table 1 indicates the levels at which the students only judged the level of participation, while the instructors judged both participation and flexibility, with the maximum being 1 and the minimum 5.

Table 1. Participation Levels

\begin{tabular}{ccc}
\hline \multicolumn{3}{c}{ LEVELS } \\
\hline 2 variables & Students & Instructors \\
\hline Participation & 4,18 & 3 \\
Flexibility & & 3.2 \\
\hline
\end{tabular}

Participation levels for Students and Instructors 
According to the instructors, the levels of participation and flexibility were between 3 and 3.2, indicating that they considered the courses to be flexible and that they enabled students to participate actively. In contrast, the value assigned by the students was close to 5 , indicating that they considered the participation in the courses to be mediocre.

Table 2. Analysis of Instructors Data

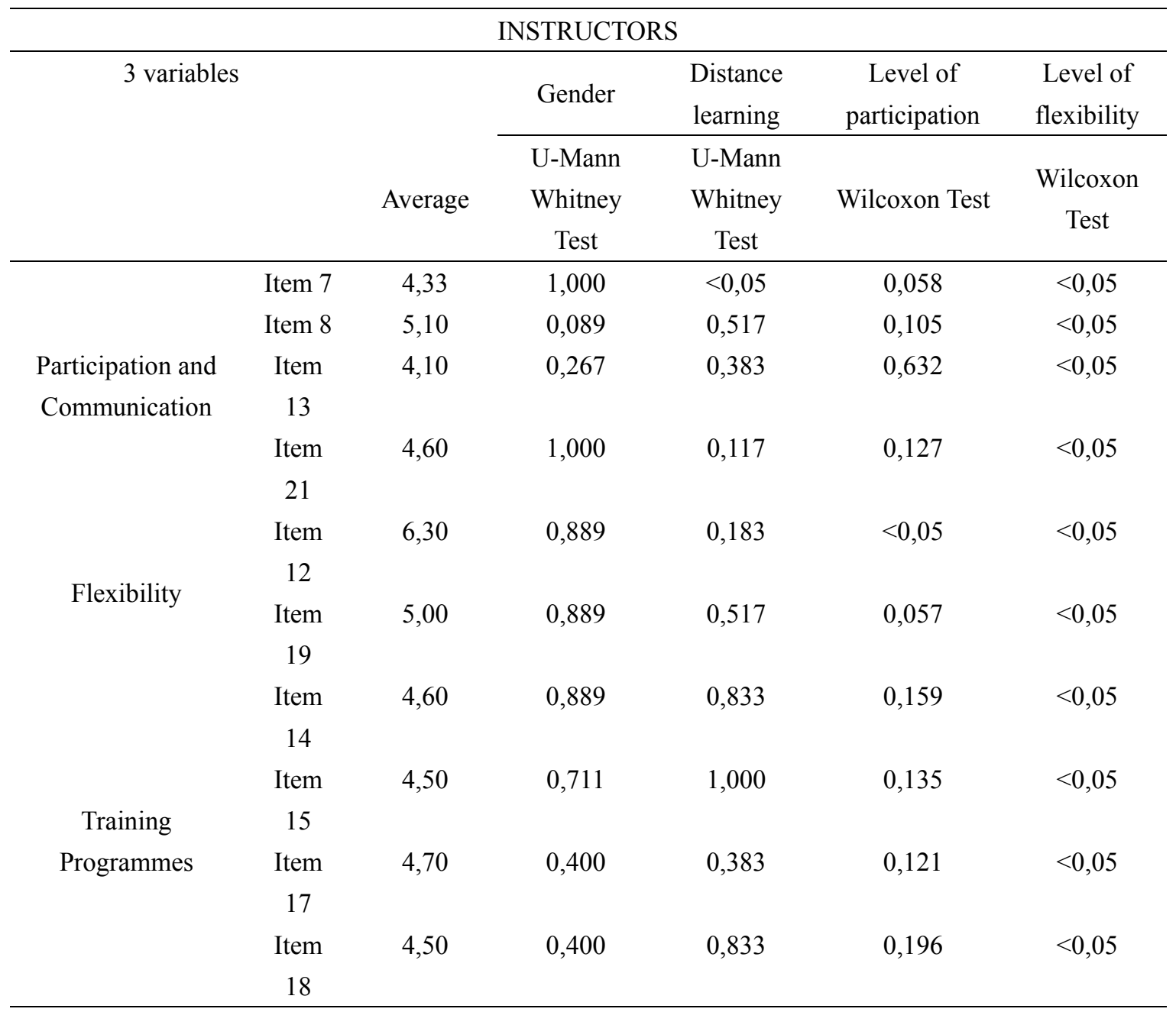

Analysis for Instructors data according to 3 variables

In Table 2, the column relating to averages refers to the values that the instructors assigned to the power field in each of the concepts that the questionnaire focused on. Thus, we can see that the values chosen are close to an average of 5, apart from flexibility (only with Item12), for which the average value assigned is 6.30 . So there is a distancing between the power field and the perception of the flexibility of the courses.

With regard to participation in the courses, it is worth highlighting the significant differences between instructors with experience and those without. Instructors who are experienced in distance learning considered the courses to be participatory. The column relating to the level of flexibility in which all concepts present significant differences requires special attention. Table 3 presents the quantitative data for the student body. 
Table 3. Analysis of Student Data

\begin{tabular}{|c|c|c|c|c|c|c|c|c|c|c|}
\hline \multicolumn{11}{|c|}{ Students } \\
\hline \multirow{2}{*}{\multicolumn{2}{|c|}{4 variables }} & \multirow{2}{*}{ Average } & \multicolumn{3}{|c|}{ Gender } & \multicolumn{2}{|c|}{$\begin{array}{l}\text { Distance } \\
\text { Education }\end{array}$} & \multicolumn{3}{|c|}{ Participation level } \\
\hline & & & $\begin{array}{c}\text { Levene } \\
\text { Test }\end{array}$ & ANOVA & $\begin{array}{l}\text { Wilcox } \\
\text { on Test }\end{array}$ & $\begin{array}{c}\text { Levene } \\
\text { Test }\end{array}$ & ANOVA & $\begin{array}{r}\text { Levene } \\
\text { Test }\end{array}$ & ANOVA & $\begin{array}{l}\text { Wilcox } \\
\text { on Test }\end{array}$ \\
\hline \multirow{2}{*}{$\begin{array}{l}\text { Participation } \\
\text { and } \\
\text { Communica } \\
\text { tion }\end{array}$} & Item 9 & 4,41 & 0,920 & 0,228 & & $>0,05$ & 0,243 & $<0,05$ & & 0,173 \\
\hline & $\begin{array}{c}\text { Item } \\
12\end{array}$ & 4,35 & 0,168 & 0,461 & & 0,353 & 0,488 & 0,561 & $<0,05$ & \\
\hline \multirow{3}{*}{$\begin{array}{l}\text { Daily } \\
\text { Lives }\end{array}$} & $\begin{array}{c}\text { Item } \\
13\end{array}$ & 4,13 & 0,622 & 0,762 & & 0,265 & 0,245 & 0,063 & $<0,05$ & \\
\hline & $\begin{array}{c}\text { Item } \\
14\end{array}$ & 4,26 & 0,119 & 0,952 & & 0,457 & 0,229 & 0,364 & $<0,05$ & \\
\hline & $\begin{array}{l}\text { Item } \\
15\end{array}$ & 4,57 & 0,336 & 0,260 & & 0,302 & 0,079 & 0,593 & 0,051 & \multirow{3}{*}{0,055} \\
\hline Flexibility & $\begin{array}{c}\text { Item } \\
21\end{array}$ & 3,73 & $<0,05$ & & 0,200 & 0,383 & 0,158 & $<0,05$ & & \\
\hline $\begin{array}{c}\text { Training } \\
\text { programmes }\end{array}$ & $\begin{array}{l}\text { Item } \\
24\end{array}$ & 4,82 & 0,942 & 0,566 & & 0,813 & 0,061 & 0,085 & 0,860 & \\
\hline
\end{tabular}

Analysis of Student data according to 4 variables

In Table 3, the column showing the averages gives an average value of 5, which means that as far as the concepts are covered by the questions, the student body is close to the power field, that is, influenced by it. Among these averages, the one that stands out is flexibility, which has an average rating of 3.73. It is precisely in relation to flexibility that we can see that the values given do not reflect the homocedasticity of the sample either with regard to gender or the level of participation, as the Leven test is lower than 0.05 . We must consider other analyses, specifically the Wilcoxon test, which is a nonparametric analysis.

Significant values can be found in relation to daily life. Thus, for students who feel that their level of participation in the courses is low, the concept of daily life is linked to power. This is in contrast to students with a higher level of participation, whose daily lives are not influenced by power.

\subsection{Qualitative}

\subsubsection{Participation and Communication}

Participation and communication are presented together, as they appear as a single category in our reference materials. Among other items, participants were asked about the level of participation that they attributed to themselves in their courses. The level is high or very high 
in the case of instructors, with the average being 3 in a scale of 1 (complete) to 10 (none). In the case of the students, the average is below 3, indicating that student respondents attribute a high level of participation to themselves in the courses. As for communication, the instructors largely use the telephone to contact the coordinator and email to contact other groups. For the students, the platform is the preferred tool.

The instructors consider meetings with colleagues as well as the chats and forums available on the platform to be necessary. However, they are not in the habit of using the tools such as videoconferences. Instructors do not think it necessary to establish communication with other instructors ("I don't need to communicate with my colleagues, only with the coordinator. In case of needing to communicate I use the phone," Instructor \#1). With reference to this final point, some instructors say they do not feel isolated. This is because they consider that the presential sessions are sufficient to build relationships with other participants and other instructors, who, as they are the only professionals in their speciality, say they are lonely rather than isolated. Nevertheless, there are instructors who consider themselves to be isolated, as is the case with Instructor \#9 ("I am the only instructor in this specialty. I often meet with my colleagues in face-to-face sessions. Unfortunately, we are all very busy and we don't have much time to talk")

\subsubsection{Daily Lives}

Data concerning the impact of courses on the daily lives of the students are shown in the economic effort they expend. Largely, expenditures center around two main axes: payment of the enrollment fee and travelling and accommodation during presential events. These amounts are determined by the students' personal situations. This includes a wide range of possibilities, from zero expenditure to maximum expenditure, although everyone concurs with regard to the benefits obtained at the end of the course.

Most students designate their home, or a space within their family dwelling, as the place where they connect to the platform and study. However, workplaces or study-oriented areas such as public libraries or universities are also used to get information and updates concerning the course. Students connect most at night, though some connections occur in the morning and afternoon. Some students say that the weekend is the only time they have to connect and communicate with the other participants in the course. Some students have no regular Internet access and are unable to access the platform for weeks.

Making the course compatible with other everyday activities involves enormous effort and determination, especially in relation to the amount of free time that students have. For some students, the effort is concentrated at specific times, such as close to the time when assignments must be submitted through the platform, and especially when they are required to attend face-to-face sessions. For others, these specific times are precisely when they do not have Internet access.

When information submitted by the students is being processed, it should be uploaded by the course coordinator. The coordinator holds that time-management skills are necessary for the course to be completed effectively not only on the part of students but also on part of 
instructors, as some hours need to be set aside every day during the course of the week for the training that the course in question provides.

\subsubsection{Flexibility}

In the category of flexibility, students and instructors were asked about the scheduling flexibility that a distance-learning course facilitates and about possible improvements that could be made. In addition, instructors were also asked about the level of flexibility provided by the course in which they were performing their role as instructors.

Out of all the instructors asked, only one answered that the course was not flexible with regard to scheduling, as this instructor felt that he or she had to be at the students' disposal on a $24 / 7$ basis. The view expressed by this one teacher was echoed by others who, while still considering the course to be flexible, felt that meeting all the deadlines limits the time available to them to run their courses. For students, flexibility was rated in a range from minimal to good, and they suggested improvements such as extending the deadlines for submitting assignments, timed assignments, publishing content, and other related activities.

\subsubsection{Training Programs}

Only a few students responded that they knew the content and had consulted the training programs before commencing the course. Only a few of these knew the names of the different subjects. Some students obtained their information directly from a document published at the BOE that described course objectives and content for each of the areas. In the questionnaire for the instructors, the items relating to this category were related to the preparation, development, and validation of the content of the training programs. As the instructors were professionals in their sports, they stated that they studied information relating to their own subject along with that of others as well as validated their material by professionals in their own field. Most instructors already had experience running seminars and trainings, and this served as a valuable preparation for the development of their course content. At the end of the course, the instructors planned to change, complete, expand, or modify sections of the subject matter as well as some evaluative activities presented to the students.

The instructors were conscious that their content was determined by certain training programs, which conditioned the way in which they taught their courses. Therefore, they proposed to make certain improvements, as some sections were not necessary for the first level and they felt that certain key elements that were relevant for the training were missing. They concurred that the number of hours should be increased.

Specifically, the instructors indicated the changes they would make to the training programs, increasing the number of hours in different subjects and allocating more time to practical aspects. Some of them felt that different sections should be grouped together within the content and that the material should be compared among different subjects to avoid repetition. This would contribute to complementing the information made available to the students. Instructors in different specializations also proposed reducing the amount of time for tactics or even eliminating it entirely, as it was a beginners' course. They felt that individual technical aspects were more important. 
The instructors' responses revealed that the training programs required improvement, and instructors should be given the opportunity to modify them in accordance with their knowledge, as these programs did not reflect the knowledge of the current teaching body, resulting in differences in the way they are presented.

\section{Discussion}

Increasing the students' level of participation should be made a priority, as they experience relationships of power and inequality with a sense of imposition. Courses should be planned and organized such that the students feel that they are a part of them (Fredericksen, Pickett, Pelz, Swan, Shea, 1999). This would serve to enhance students' motivation and their degree of satisfaction (Weller \& Anderson, 2013) and to maintain a high level of expectation with regard to the acquisition of knowledge in accordance with their training needs.

Resistance is generated in students who do not have Internet access, which results in a digital gap between those who have regular Internet access and those who do not. Furthermore, the training period should be increased from three months to a period that would be sufficient for anyone to follow a course irrespective of whether they have ready access to the Internet (for instance emphasizing on process and motivational scaffolds, Cheng, Yang, Liao, Chang, Huang, Chan, 2015); besides, student access to the Internet should be a relevant item of information in determining whether a longer training period should be made available.

The source of the instructors' resistance has to do with the structuring of the content (which is determined by ministerial decree). They can be satisfied with the content as long as it is sufficiently flexible (Onyilagha \& Nnajifor, 2016) to enable them to adapt it to their knowledge (Dhilla, 2016; Gay, 2016).

We conclude, therefore, that administrators must ensure that their courses are sufficiently flexible from the instructors' perspective, as this would enhance their satisfaction and minimize resistance (Dialogical Theory, Hermans, 1999). Increasing course flexibility with a view to facilitating the acceptance of new technologies is essential, as this would contribute to conflict resolution and minimize possible resistance.

While instructors are aware of the tools and the opportunities offered by the distance learning model, they lack knowledge of the full potential of these tools (Onyilagha \& Nnajifor, 2016) or have the belief that they are not entirely necessary. The instructors consider the following measures to be indispensable to prevent resistance from being generated: holding regular meetings to share experiences and knowledge, opening a common space through which the instructors can be in constant contact with each other throughout their courses to facilitate the exchange of information, and being able to share questions about their courses.

As the more constrained students feel their participation to be and the more restricted their communication with other participants, the more alienated they feel in their experience of online training. Thus, communication and participation must be promoted to reduce resistance. In addition, personal issues in the use of the platform should be considered as a 
generator of resistances. These personal issues can be addressed through practical sessions for using the platform or tutorials or guides aimed at those who have little practical experience in the use of distance learning technology or any technology. The instructors commented that they keep up to date with new technologies outside their technical courses. This process of self-updating could be useful to provide training for instructors, taking full advantage of the potential of the platform as well as the needs of individual instructors.

On the other hand, instructors do not need to be constantly available, so time slots should be scheduled for students (Alghazo, 2006) and dates must be established for the provision and exchange of information.

\section{Conclusions}

Students lack face-to-face opportunities both with their fellow students and with their instructors. Interaction is limited, as it only occurs in the face-to-face sessions. This is partly due to the minimal use that the instructors make of the communicative tools available in the platform itself and the fact that the instructors have not fully mastered the use of these tools for their courses. This lack of contact and interaction leads to apprehension and uncertainty, which is the first step toward resistance arising if the problem is not tackled. This lack of interaction is compounded by the inadequate flow of information that the participants highlighted, which is partly the result of the insufficient use of the tools available on the platform and of their excessive slowness.

The training programs generate resistance insofar as the instructors feel that they are not appropriate or do not agree with them, with the result that they do not recommend them to the students and transmit their feelings to the students either explicitly or implicitly. For example, instructors do not consider it necessary to have an area for the training programs at the beginner level and do not give it any priority in training, with the result that the students feel that this area is unnecessary and bears little relation to the knowledge that they are acquiring.

Other generators of resistance among the students include not being able to access the Internet during the courses. The lack of Internet access influences the students' schedules and study spaces, as a result of which flexibility, which is precisely an advantage the distance model offers, is reduced. This lack of Internet gives rise, within the student body, to a digital gap, as it not only reduces flexibility but also limits participation. Students in this situation manage to find spaces with free Internet access as a means of dealing with this problem. These spaces are usually public libraries, universities, educational centers, and the homes of family members. Due to limitations of access, students tend to request extensions for deadlines to be able to follow their training adequately.

Some students experience a feeling of loneliness; sources of resistance include feeling isolated from other participants, which is compounded by the belief that they are inadequately informed. Mostly, students tackle this isolation by approaching acquaintances (whether instructors or other students) before beginning a course for solving problems and obtaining information. 
From the students' perspective, the lack of participation requires a greater use of audiovisual media to provide opportunities for synchronic interaction, which they feel would increase their level of participation. Simultaneously, the group of participants who exchange information appoint information agents who can obtain new information in advance and pass it on to others.

Contact from instructors should be increased via regular messages being sent out to all students or by sending informative documents concerning changes that have been made to the information provided at the outset of the course. This shared information is currently often conveyed through communicative tools that are external to the course platform, which is not conducive to extending the use of the platform. Finally, and contrary to what one might think, the economic expenditure required to complete the course is not a determining factor in the generation of resistance.

The contribution of the instructors is their perception that they have to be available $24 \times 7 \times 365$. This is a generator of resistance. This perception must be overcome by better management of time devoted to the courses and by deciding in advance which hours of the day instructors will devote to the course. Resistance also stems from a lack of adequate engagement with the face-to-face sessions, whether it be the physical presence on a track or in a classroom or the leisure time during which one can chat with other participants and get to know them better. In addition, instructors should learn how to take full advantage of the course platform instead of diversifying to other technologies, which unnecessarily increase their work load.

The Royal Spanish Skating Federation has begun a new era in training its sport technicians. Changing its long tradition of instruction requires time and the involvement of the participants in the avoidance of power resistance.

\section{References}

Alghazo, I. (2006). Quality of Internet use by teachers in the United Arab Emirates. Education, 126(4), 769-781.

Bell, N., \& Baron, E. (2015). Resistance to peer influence during adolescence: Proposing a sociocultural-developmental framework. New Ideas in Psychology, 39, 53-62. http://dx.doi.org/10.1016/j.newideapsych.2015.07.005

Bourdieu, P., \& Nice, R. (1998). Acts of resistance. New York: New Press.

Bulfin, S., Pangrazio, L., \& Selwyn, N. (2014). Making 'MOOCs': The construction of a new digital higher education within news media discourse. The International Review of Research in Open And Distributed Learning, 15(5). http://dx.doi.org/10.19173/irrodl.v15i5.1856

Caruth, G., \& Caruth, D. (2013). Understanding resistance to change: A challenge for Universities. Turkish Online Journal of Distance Education, 14(2), 12-21.

Cheng, H., Yang, E., Liao, C., Chang, B., Huang, Y., \& Chan, T. (2015). Scaffold Seeking. 
Journal Of Educational Computing Research, 53(3), 409-435. http://dx.doi.org/10.1177/0735633115601598

Creswell, J. (2014). Research design. Qualitative, Quantitative and Mixed Methods approaches. Thousand Oaks, California: SAGE Publications.

Dent, E., \& Goldberg, S. (1999). Challenging 'Resistance to Change'. SSRN Electronic Journal, 35(1). http://dx.doi.org/10.2139/ssrn.2326329

Denzin, N., \& Lincoln, Y. (2005). The SAGE handbook of qualitative research. Thousand Oaks: Sage Publications.

Dhilla, S. (2016). Using Mezirow's transformative learning theory to understand online instructors' construction of the virtual teaching experience. Ph. D. Thesis. Boston University.

Emo, W. (2015). Teachers' motivations for initiating innovations. Journal of Educational Change, 16(2), 171-195. http://dx.doi.org/10.1007/s10833-015-9243-7

Foucault, M. (1978). Microphysics of power. Madrid: La Piqueta.

Foucault, M. (2012). A dialogue on power and other conversations. Madrid: Alianza Editorial.

Fredericksen, E., Pickett, A., Pelz, W., Swan, K., \& Shea, P. (1999). Student satisfaction and perceived learning with online courses. Principles examples from the SUNY learning network. The State University of New York.

Gay, G. (2016). An assessment of online instructor e-learning readiness before, during, and after course delivery. Journal of Computing in Higher Education, 28(2), 199-220. http://dx.doi.org/10.1007/s12528-016-9115-z

Giroux, H. (2001). Theory and resistance in education. Westport, Conn.: Bergin \& Garvey.

Hermans, H. (1999). Dialogical thinking and self-innovation. Culture \& Psychology, 5(1), 67-87. http://dx.doi.org/10.1177/1354067x9951004

Kahneman, D., \& Tversky, A. (1979). Prospect theory: An analysis of decision under risk. Econometrica, 47(2), 263. http://dx.doi.org/10.2307/1914185

MacFayden, L., \& Dawson, S. (2012). Numbers are not enough. Why e-learning analytics failed to inform an institutional strategic plan. Educational Technology \& Society, 15(3), 149-163.

Margolis, H. (1991). Understanding, Facing Resistance to Change. NASSP Bulletin, 75(537), 1-8. http://dx.doi.org/10.1177/019263659107553702

Olafson, L. (2006). It's just easier not to go to school. Adolescent girls and disengagement in middle school. New York: Peter Lang.

Onyilagha, J., \& Nnajiofor, F. (2016). Comparative study of the impact of instructional 
materials and technology on traditional and distance education systems. International Journal for Innovation Education and Research, 4(2), 71-78.

Parlakkilic, A. (2016). E-learning change management: Challenges and opportunities. Turkish Online Journal of Distance Education, 14(4), 54-68.

Sharp, J. (2000). Entanglements of power: Geographies of domination/resistance. In J.P. Sharp, P. Routledge, C. Philo \& R. Paddison (Eds.), Entanglements of power (pp. 1-42). New York, NY: Routledge.

Szeto, E. (2013). Examining issues of e-learning practices in Chinese higher education: A comparative study of Mainland China, Hong Kong and Taiwan. International Journal on E-Learning, 12(4), 383-402.

Walala, S. (2016). Effect of change management capacity on the delivery of quality education in public technical and vocational institutions in Kenya ( $\mathrm{PhD}$ Thesis). Jomo Kenyatta University of Agriculture and Technology.

Walker, B., Holling, C., Carpenter, St., \& Kinzig, A. (2004). Resilience, adaptability and transformability in social-ecological systems. Ecology and Society, 9(2). https://doi.org/10.5751/ES-00650-090205

Weller, M., \& Anderson, T. (2013). Digital resilience in higher education. European Journal of Open, Distance and E-Learning, 16(1), 53-66.

\section{Copyright Disclaimer}

Copyright for this article is retained by the author(s), with first publication rights granted to the journal.

This is an open-access article distributed under the terms and conditions of the Creative Commons Attribution license (http://creativecommons.org/licenses/by/3.0/). 